\title{
Feasibility of quantifying SDC2 methylation in stool DNA for early detection of colorectal cancer
}

Tae Jeong Oh', Hyun II Oh${ }^{1}$, Yang Yei Seo ${ }^{1}$, Dongjun Jeong ${ }^{2}$, Changjin Kim², Hyoun Woo Kang ${ }^{3}$, Yoon Dae Han ${ }^{4}$, Hyun Cheol Chung ${ }^{5}$, Nam Kyu Kim ${ }^{4}$ and Sungwhan $\mathrm{An}^{1 *}$ (D)

\begin{abstract}
Background: Colorectal cancer (CRC) screening is the most efficient strategy to reduce disease-related mortality. Frequent aberrant DNA methylation is known to occur in selected genes and early during CRC development, which has emerged as a new epigenetic biomarker for early detection of CRC. Previously, we reported that we identified that CpG sites of SDC2 were aberrantly methylated in tumor tissues of most CRC patients through comprehensive methylation analysis and demonstrated a high potential of quantification of SDC2 methylation in blood for early detection of colorectal cancer. In this study, we aim to investigate the feasibility of quantifying SDC2 methylation in stool DNA for the early detection of CRC. The objective of this study was to confirm a high frequency of SDC2 methylation in tumor tissues at various stages of CRC and investigate the feasibility of a quantitative test for SDC2 methylation in fecal DNA by highly sensitive and accurate real-time PCR for early detection of CRC.
\end{abstract}

Methods: Bisulfite-pyrosequencing assay was performed to measure the SDC2 methylation status in tissue samples. For methylation analysis in stool DNA, a highly sensitive and accurate method was applied which implements consecutive two rounds of PCR consisting of unidirectional linear target enrichment (LTE) Of SDC2 and quantitative methylation-specific real time PCR (qMSP) for SDC2, named as meSDC2 LTE-qMSP assay. Its limit of detection was 0. $1 \%$ methylation (corresponding to $\sim 6$ copies in total $\sim 6200$ genome copies).

Results: Positive SDC2 methylation was observed in 100\% of primary tumors, $90.6 \%$ of adenomatous polyps, $94.1 \%$ of hyperplastic polyps, and 0\% of normal tissues. SDC2 methylation level also significantly $(P<0.01)$ increased according to the severity of lesions. In stool DNA test for SDC2 methylation by LTE-qMSP comparing CRC patients with various stages (I to IV) $(n=50)$ and precancerous lesions $(n=21)$ with healthy subjects $(n=22)$, the overall sensitivity was $90.0 \%$ for detecting CRC and 33.3\% for detecting small polyps, with a specificity of 90.9\%.

Conclusions: Taken together, our result indicates that stool DNA-based SDC2 methylation test by LTE-qMSP is a potential noninvasive diagnostic tool for early detection of CRC.

Keywords: Colorectal cancer, Early detection, Methylation, Precancerous lesion, SDC2, Stool DNA

\footnotetext{
* Correspondence: genomictree1@korea.com

${ }^{1}$ Genomictree, Inc, 44-6 Techno 10-ro Yuseong-gu, Daejeon 34027, South

Korea

Full list of author information is available at the end of the article
} 


\section{Background}

Colorectal cancer (CRC) is the second most common cause of malignant deaths in industrialized countries, and it is known to be major cause of cancer morbidity and mortality $[1,2]$. The 5-year survival rate for CRC can be as high as $90 \%$, if the cancer is detected at an early stage, but it is estimated to be less than $10 \%$ if a metastasis occurs [3]. Several CRC screening tools have been developed to facilitate the early detection of CRC, including colonoscopy and fecal occult blood testing (FOBT) [4]. For the last 10 years, colonoscopy has been preferred as a screening tool to detect CRC early [5]. However, the acceptance of screening colonoscopy remains very low within the general public, for several reasons including the need for extensive bowel preparation [4]. Meanwhile, noninvasive stool tests such as immunochemical FOBT have been available so far as an attractive alternative to screen people for colonoscopy referral. However, this has limited use as a screening test to detect of earlier stages of CRC because of its low sensitivity in detecting stage I of CRC and advanced adenoma, at 53 and 27\%, respectively [6]. Thus, significant efforts have been made to develop noninvasive molecular tests using accurate molecular biomarkers to detect CRC and colorectal adenomas at an early stage [7].

The aberrant methylation of genes is an epigenetic change that induces gene silencing of tumor suppressor genes, and it has been recognized as one of the most common molecular alterations in CRC and in other human cancers [8-10]. Methylated DNA is known to be chemically and biologically stable, it is less subjected to transient alterations, and it is readily detectable in many types of body fluids including blood and stool. Therefore, aberrantly methylated specific DNA sites in solid tumors are well suited as noninvasive molecular diagnostics for the early cancer detection [11-13].

Several stool-based DNA methylation markers such as TFPI2, VIM, SFRP2, NDRG4, BMP3, and SDC2 have been previously described as potential markers for early CRC detection [14-18]. Overall, these reports presented sensitivities of 46 to $89 \%$ and specificities of 76.8 to $93 \%$. Notably Imperiale et al. [19] recently reported a new stool DNA test to measure two methylation biomarkers and seven site mutations of KRAS in addition to a hemoglobin test in the stool sample. This combinatorial test showed an overall sensitivity of $92 \%$ with a specificity of $87 \%$ for CRC detection, and it was approved by the US FDA in 2014.

We previously determined that normally unmethylated CpG sites of SDC2 are predominantly methylated in tumor tissues of CRC and subsequently demonstrated that the aberrant methylation of $S D C 2$ is frequently detected in serum DNA derived from CRC patients, but rarely in healthy subjects, indicating potential as a biomarker for early diagnosis of CRC [20]. The syndecan-2 (SDC2) protein functions as an integral membrane protein and participates in cell proliferation, cell migration, and cell-matrix interactions via its receptor for extracellular matrix proteins [21, 22]. In this study, we used a bisulfite-pyrosequencing methylation assay on an independent group of CRC patients to confirm the high prevalence of aberrant $S D C 2$ methylation in tumor tissues of CRC patients and precancerous biopsies with various stages compared to those of normal tissues. For the clinical validity of stool-based SDC2 methylation assay in detecting $\mathrm{CRC}$, we introduced a very sensitive and accurate method that consists of quantitative methylation-specific PCR coupled with linear target enrichment (LTE-qMSP). The clinical validity of the early CRC detection using LTE-qMSP for SDC2 methylation in stool DNA was assessed by comparing observation for patients with various stages of CRC and precancerous lesions to those of healthy individuals. The results indicated that SDC2 methylation has high potential as a biomarker useful in noninvasive diagnostics of early-stage CRC.

\section{Methods \\ Reagents}

All chemical reagents used were purchased from SigmaAldrich (MO, USA) unless otherwise noted. Oligonucleotides and fluorescent probes were synthesized by Integrated DNA Technologies (Iowa, USA).

\section{Cell line and clinical specimens}

Human colon cancer cell HCT116, SW480, and HT-29 were obtained from Korean Cell Line Bank (Seoul, South Korea) and maintained in RPMI 1640 medium (JBI, Seoul, South Korea) supplemented with $10 \%$ fetal bovine serum (JBI, Seoul, South Korea), $100 \mathrm{unit} / \mathrm{mL}$ of penicillin (JBI, Seoul, South Korea), and $100 \mu \mathrm{g} / \mathrm{mL}$ of streptomycin (JBI, Seoul, South Korea) in a humidified incubator at $37{ }^{\circ} \mathrm{C}$ with $5 \% \mathrm{CO}_{2}$.

Paraffin sections of polyp tissues $(n=49)$ and freshfrozen sections of primary colorectal tumor tissues $(n=$ 18) were obtained from College of Medicine, Soonchunhyang University (Chonan, South Korea). Briefly, tissue blocks were cut with a standard microtome (Leica Biosystems, Nussloch, Germany) to generate successive sections. They were mounted onto adhesive silanecoated slides. Polyp and tumor components were identified and marked on hematoxylin and eosin stained sections for further DNA studies by an expert surgical pathologist. Genomic DNA $(n=5)$ from normal mucosa without any history of malignancy were purchased from BioChain Institute (CA, USA).

Stool samples from patients with histology-confirmed CRC $(n=50)$, adenomatous polyps $(n=21)$, and healthy 
normal subjects without any history of malignancy ( $n=$ 22) were obtained from Cancer Center of Yonsei University College of Medicine (Seoul, South Korea) and Dongguk University Ilsan Hospital (Ilsan, South Korea). All stool samples were collected prior to colonoscopy or purgative bowel preparation. The collection paper (JeongHyun MED, Seoul, South Korea) mounted to the toilet seat was used to prevent contamination of toilet water. Approximately $10 \mathrm{~g}$ of a single stool from each individual was collected from four to five different spots in $20 \mathrm{~mL}$ of preservative buffer (Genomictree, Inc., Daejeon, South Korea) using spatula. All stool samples were stored at $4{ }^{\circ} \mathrm{C}$ until used. Detailed characteristics of enrolled patients are summarized in Table 1. This study was approved by the Institutional Review Board of College of Medicine of Soonchunhyang University,

Table 1 Clinicopathological features of colorectal tissue and stool samples used in this study

\begin{tabular}{|c|c|c|}
\hline \multirow[t]{2}{*}{ Characteristics } & \multicolumn{2}{|c|}{ Number of patients (\%) } \\
\hline & Tissues & Stool \\
\hline Healthy normal & $n=5$ & $n=22$ \\
\hline \multicolumn{3}{|l|}{$\operatorname{Sex}(\%)$} \\
\hline Male & $4(80.0)$ & $12(54.5)$ \\
\hline Female & $1(20.0)$ & $10(45.5)$ \\
\hline Age, mean (range) & $55.5(48-65)$ & $58.8(36-77)$ \\
\hline Polyp & $n=49$ & $n=21$ \\
\hline \multicolumn{3}{|l|}{$\operatorname{Sex}(\%)$} \\
\hline Male & $37(75.5)$ & $13(61.9)$ \\
\hline Female & $12(24.5)$ & $8(38.1)$ \\
\hline Age, mean (range) & $57.2(28-89)$ & $63.4(51-75)$ \\
\hline \multicolumn{3}{|c|}{ Number of polyps analyzed from each patient (range, 1-6) (\%) } \\
\hline 1 & $21(42.9)$ & $3(14.3)$ \\
\hline $2-3$ & $23(46.9)$ & $15(71.4)$ \\
\hline$\geq 4$ & $5(10.2)$ & $3(14.3)$ \\
\hline \multicolumn{3}{|l|}{ Histopathology } \\
\hline Hyperplastic & $17(34.7)$ & \\
\hline Tubular & $27(84.3)$ & $21(100)$ \\
\hline Tubularvillous & $5(15.7)$ & \\
\hline CRC & $n=18$ & $n=50$ \\
\hline \multicolumn{3}{|l|}{$\operatorname{Sex}(\%)$} \\
\hline Male & $8(40.0)$ & $30(60.0)$ \\
\hline Female & $12(60.0)$ & $20(40.0)$ \\
\hline Age, mean (range) & $63.1(39-80)$ & $61.9(41-84)$ \\
\hline \multicolumn{3}{|l|}{ Stage (\%) } \\
\hline । & $2(10.0)$ & $12(24.0)$ \\
\hline$\|$ & $12(60.0)$ & $17(34.0)$ \\
\hline III & $2(10.0)$ & $10(20.0)$ \\
\hline IV & $4(20.0)$ & $11(22.0)$ \\
\hline
\end{tabular}

Dongguk University Ilsan Hospital, and Cancer Center of Yonsei University College of Medicine. Written informed consent was obtained from all study participants, adhering to local ethics guidelines.

\section{DNA isolation}

For fresh-frozen tissues, specimens were embedded in Tissue-Tek O.C.T compound (Sakura Finetek, Torrance, USA) and frozen at $-20{ }^{\circ} \mathrm{C}$ in cryostat chamber (Leica Biosystems, Nussloch, Germany). Five to seven frozen tissue sections (12 $\mu \mathrm{m}$ in thickness) and four to six sections $(10 \mu \mathrm{m}$ in thickness) of formalin-fixed paraffinembedded (FFPE) tissues were prepared using microtome (Leica Biosystems, Nussloch, Germany). To remove paraffin for FFPE sections, $1.0 \mathrm{~mL}$ of xylene was added to paraffin sections in $2.0 \mathrm{~mL}$ of microcentrifuge tubes and incubated at room temperature for $10 \mathrm{~min}$. Tubes were centrifuged at $12,000 \times g$ for $10 \mathrm{~min}$ at room temperature, and the supernatant was discarded. This process was repeated until paraffin was fully removed. One milliliter of ethanol was added to each tube and vigorously shaken to wash out xylene, followed by centrifugation at $12,000 \times g$ for $10 \mathrm{~min}$. This was repeated three times. All genomic DNA was isolated from tissues and cell lines using QiaAmp DNA Mini kit (QIAGEN, Hilden, Germany) according to manufacturer's instructions.

All stool samples were washed in excess volume of PBS at once and homogenized in EDTA-based buffer solution $(1 \mathrm{~mL}$ solution per $0.6 \mathrm{~g}$ of stool) with a shaker device. After homogenization, $1 \mathrm{~g}$ equivalent of each stool was centrifuged. The supernatants were removed and added 1.0 to $1.4 \mathrm{~mL}$ of lysis buffer 1 (Genomictree, Inc., Daejeon, South Korea) to the pellet and incubated for $4 \mathrm{~min}$ at room temperature. The samples were centrifuged and removed the supernatant, followed by addition of lysis buffer 2 (Genomictree, Inc., Daejeon, South Korea). The samples were incubated for $2 \mathrm{~min}$ at room temperature and centrifuged. $0.75 \mathrm{~mL}$ of the supernatant was aliquoted and added $25 \mu \mathrm{L}$ of proteinase $\mathrm{K}(0.4 \mathrm{mg} / \mathrm{mL})$ and incubated at $70{ }^{\circ} \mathrm{C}$ for $10 \mathrm{~min}$. The samples were subsequently extracted with trissaturated phenol-chloroform-isoamylalcohol (25:24:1 by volume) (Thermo Scientific, MA, USA). Total nucleic acids were then precipitated (1/10 volume of $3 \mathrm{~mol} / \mathrm{L}$ sodium acetate and equal volume of isopropanol, removed from solution by centrifugation. The DNA pellet was washed with $70 \%$ ethanol and dried. The DNA samples were dissolved in 50 to $100 \mu \mathrm{L}$ of TE buffer and stored at $-20{ }^{\circ} \mathrm{C}$. Stool DNA was also extracted using QIAamp DNA Stool Mini Kit (QIAGEN, Hilden, Germany) according to manufacturer's instruction and finally eluted with $50 \mu \mathrm{L}$ of elution buffer. Initial homogenization steps are same and $0.2 \mathrm{~g}$ of stool was used for DNA extraction. The DNA concentration 
was measured by Qubit dsDNA BR assay kit (Thermo Scientific, MA, USA).

\section{Bisulfite treatment}

Genomic DNA was chemically modified with sodium bisulfite to convert all unmethylated cytosine to uracil while leaving methylated cytosine unmodified using EZ DNA Methylation-Gold kit (ZYMO Research, CA, USA) according to manufacturer's instructions. Briefly, genomic DNA was treated with sodium bisulfite at $65^{\circ} \mathrm{C}$ for $2.5 \mathrm{~h}$. Desulfonation was performed at room temperature for 20 min. Bisulfite-converted DNA was purified using Zymo-Spin IC column (Zymo Research, CA, USA) and eluted with $10 \mu \mathrm{L}$ of distilled water. The eluted DNA was either used immediately for methylation analysis or stored at $-20{ }^{\circ} \mathrm{C}$ until further use.

\section{Bisulfite-pyrosequencing methylation assay of SDC2 gene in tissues}

To quantify methylation levels of $S D C 2$, quantitative bisulfite-pyrosequencing was performed. Specific bisulfite PCR and pyrosequencing primers were designed to analyze $149 \mathrm{bp}$ of $5^{\prime}$ regulatory region including four $\mathrm{CpG}$ dinucleotides sites $(+456,+460$, +466, +473 bp) of SDC2 gene using PyroMark Assay Design Software v. 2.0 (QIAGEN, Hilden, Germany). The following primers were used: forward, 5'GGGAGTAGGAGTAGGAGGAGGAA-3'; reverse, 5' Biotin-ACCAAAACAAAA CCAAACCTCCTACCCA3'; sequencing primer, 5'-AGGAGGAGGAAGAGAG$3^{\prime}$. Briefly, $20 \mathrm{ng}$ of bisulfite-modified DNA was amplified in a $25 \mu \mathrm{L}$ reaction volume with gene-specific primers using PyroMark PCR kit (QIAGEN, Hilden, Germany). Samples were heated to $94^{\circ} \mathrm{C}$ for $10 \mathrm{~min}$ and then amplified for 45 cycles at $94^{\circ} \mathrm{C}$ for $30 \mathrm{~s}, 56^{\circ} \mathrm{C}$ for $45 \mathrm{~s}$, and $72^{\circ} \mathrm{C}$ for $40 \mathrm{~s}$. All reactions were then incubated at $72^{\circ} \mathrm{C}$ for $10 \mathrm{~min}$ for final extension. Pyrosequencing was performed using PyroMark Gold Q96 reagent and PyroMark ID96 instrument (QIAGEN, Hilden, Germany) following manufacturer's instructions. Briefly, $25 \mu \mathrm{L}$ of each biotinylated PCR product was immobilized on streptavidin-coated Sepharose HP beads (Amersham Biosciences, NJ, USA) and then subjected to sequencing using automatically generated nucleotide dispensation order of "sequence to analyze" corresponding to each reaction.

Each CpG site was assigned a percentage (\%) of methylation by evaluating $\mathrm{C} / \mathrm{T}$ ratio as methylation index (MtI). The average \% of methylation across four CpG sites was obtained. Methylated non-CpG cytosines were used as internal controls to check the fidelity of bisulfite conversion. If MtI of each sample was greater than $5 \%$ of detection limit of pyrosequencing [23], it was considered as methylation-positive.

\section{Analytic performance of meSDC2 LTE-qMSP}

Analytic performance of meSDC2 LTE-qMSP was determined for PCR replicate by testing aliquots of DNA. To examine the limit of detection (LoD) of SDC2methylated DNA, HCT116 genomic DNA as fully methylated human genomic DNA was serially diluted with an unmethylated genomic DNA. The unmethylated genomic DNA was prepared by whole genome amplification of human lymphocyte genomic DNA (BioChain Institute Inc., CA, USA) using Illustra GenomiPhi V2 DNA Amplification kit (GE Healthcare, OH, USA) [24]. For comparison of meSDC2 LTE-qMSP with our previous meSDC2-qMSP assay [20], different amounts (200, $100,50,20,10$, and $0 \mathrm{pg}$ ) of fully methylated HCT116 genomic DNA were diluted into unmethylated genomic DNA in total 20 ng of genomic DNA to create mixtures with methylation percentages of 1.0, 0.5, 0.25, 0.1, 0.05, and $0 \%$. Resultant DNA samples from each concentration were pooled and divided to multiple aliquots so that the same DNA substrate was used in PCR for comparison. meSDC2-qMSP and meSDC2 LTE-qMSP were performed in 24 replicates (8 replicates in 3 independent runs using the same real-time PCR instrument on the same day). Primers and probes used for meSDC2 LTEqMSP and meSDC2-qMSP are listed in Table 2.

\section{Methylation measurement in stool DNA by meSDC2 LTE-qMSP}

For measurement of SDC2 methylation, LTE was introduced in step 1 in order to specifically enrich methylated SDC2 target DNA from bisulfite-modified DNA. Additionally, the region lacking $\mathrm{CpG}$ dinucleotides of COL2A1 gene was used as a control [25] for estimation of the amount of amplifiable template and adequacy of bisulfite conversion. A total of $20 \mu \mathrm{L}$ of reaction mixture contained $2.0 \mu \mathrm{g}$ of bisulfite-converted stool DNA, each $0.05 \mu \mathrm{M}$ of SDC2 methylation-specific antisense and COL2A1 gene-specific antisense primers attached to 5' universal sequence, and $4 \mu \mathrm{L}$ of $5 \times$ AptaTaq PCR master mix (Roche Diagnostics, Basel, Swiss). Thermal cycling conditions were as follows: $95{ }^{\circ} \mathrm{C}$ for $5 \mathrm{~min}$ followed by 35 cycles of $95{ }^{\circ} \mathrm{C}$ for $15 \mathrm{~s}$ and $60{ }^{\circ} \mathrm{C}$ for $60 \mathrm{~s}$. After LTE, the reaction mixture volume was scaled up to $40 \mu \mathrm{L}$, containing $8 \mu \mathrm{L}$ of $5 \times$ AptaTaq PCR master mix, $0.25 \mu \mathrm{M}$ of $S D C 2$ methylation-specific sense primer, $0.125 \mu \mathrm{M}$ of $S D C 2$ probe (FAM), $0.125 \mu \mathrm{M}$ of COL2A1 sense primer, $62.5 \mathrm{nM}$ of $C O L 2 A 1$ probe (Cy5), and $0.25 \mu \mathrm{M}$ of universal sequence primer. Real-time PCR was performed on a Rotor-Gene $Q$ real-time PCR system (QIAGEN, Hilden, Germany). Thermal cycling conditions were as follows: $95^{\circ} \mathrm{C}$ for $5 \mathrm{~min}$ and then 40 cycles of $95{ }^{\circ} \mathrm{C}$ for $15 \mathrm{~s}$ and $60{ }^{\circ} \mathrm{C}$ for $60 \mathrm{~s}$. Heating and cooling rates were $20{ }^{\circ} \mathrm{C}$ per second and $15{ }^{\circ} \mathrm{C}$ per second, respectively. For each run, bisulfite-converted 
Table 2 Comparison of meSDC2 LTE-qMSP with meSDC2-qMSP

\begin{tabular}{|c|c|c|}
\hline Description & meSDC2 LTE-qMSP & meSDC2-qMSP \\
\hline $\begin{array}{l}\text { SDC2 } \\
\text { Primer sequences }\end{array}$ & $\begin{array}{l}\text { 5'-GTAGAAATTAATAAGTGAGAGGGC-3' } \\
\text { 5'-AAAGATTCGGCGACCACCGAACGACTCAAACTCGAAAACTCG-3' }\end{array}$ & $\begin{array}{l}\text { F: 5'-TAGAAATTAATAAGTGAGAGGGCGT-3' } \\
\text { R: 5'-GACTCAAACTCGAAAACTCGAA-3' }\end{array}$ \\
\hline SDC2 probe ${ }^{a}$ & 5'-FAM-TTCGGGGCGTAGTTGCGGGCGG-3' & 5'-FAM-AGTAGGCGTAGGAGGAGGAAGCGA-3' \\
\hline SDC2 amplicon size & $124 \mathrm{bp}$ & $121 \mathrm{bp}$ \\
\hline $\begin{array}{l}\text { Real time PCR } \\
\text { reagents }\end{array}$ & AptaTaq DNA Master, $5 X$ & Rotor-Gene Probe PCR Kit \\
\hline $\begin{array}{l}\text { Thermal cycling } \\
\text { condition }\end{array}$ & $\begin{array}{l}\text { LTE: } 95^{\circ} \mathrm{C} 5 \mathrm{~min} ; 95^{\circ} \mathrm{C} 15 \mathrm{~s}, 60^{\circ} \mathrm{C} 1 \mathrm{~min}, 35 \text { cycles; heating and cooling } \\
\text { rates were } 15 \text { and } 20^{\circ} \mathrm{C} / \mathrm{s} \text {. } \\
\text { qMSP: } 95^{\circ} \mathrm{C} 5 \mathrm{~min} ; 95^{\circ} \mathrm{C} 15 \mathrm{~s}, 60^{\circ} \mathrm{C} 1 \mathrm{~min}, 40 \text { cycles; heating and } \\
\text { cooling rates were } 15 \text { and } 20^{\circ} \mathrm{C} / \mathrm{s} \text {. }\end{array}$ & $\begin{array}{l}\text { qMSP: } 95^{\circ} \mathrm{C} 5 \text { min; } 95^{\circ} \mathrm{C} 10 \mathrm{~s}, 62^{\circ} \mathrm{C} 15 \mathrm{~s}, 72{ }^{\circ} \mathrm{C} 20 \mathrm{~s} \\
40 \text { cycles; heating and cooling rates were } \\
15 \text { and } 20^{\circ} \mathrm{C} / \mathrm{s} \text {. }\end{array}$ \\
\hline Control gene & COL2A1 & ACTB \\
\hline Primer sequences $^{\mathrm{a}}$ & $\begin{array}{l}\text { 5'-GTAATGTTAGGAGTATIITGTGGITA-3' } \\
\text { 5'-AAAGATTCGGCGACCACCGACTAICCCAAA AAAACCCAATCCTA-3' }\end{array}$ & $\begin{array}{l}\text { F: 5'-TGGTGATGGAGGAGGTTAAGTAAGT-3' } \\
\text { R: 5'-AACCAATAAAACCTACTCCTCCCTT AA-3' }\end{array}$ \\
\hline COL2A1 probe ${ }^{a}$ & 5'-Cy5-AGAAGAAGGGAGGGGTGTTAGGAGAGG-3' & 5'-TET-ACCACCACCCAACACACAATAACAAACA CA-3' \\
\hline $\begin{array}{l}\text { COL2A1 amplicon } \\
\text { size }\end{array}$ & $86 \mathrm{bp}$ & $133 \mathrm{bp}$ \\
\hline
\end{tabular}

Bold identical nucleotide sequences with meSDC2-qMSP assay, italics universal sequence, $I$ inosine nucleotide, $F$ and $R$ indicate forward and reverse primers, respectively

${ }^{a} \mathrm{CpG}$ dinucleotide sites are underlined

methylated (HCT116) and unmethylated genomic DNA were used as methylation controls. Non-template control was also included. Cycle threshold $\left(C_{T}\right)$ value was calculated using Rotor Gene Q software.

The cutoff value of $C_{T}$ in real-time PCR assay for $S D C 2$ methylation was chosen based on the receiver operating characteristics curve (ROC) analysis on assay results. An optimal cutoff of $C_{T}$ value for optimal sensitivity and specificity discriminating CRC patients from healthy subjects was determined at 40 . Therefore, in interpreting LTE-qMSP assay for $S D C 2$ methylation, if $C_{T}$ value was within 40 cycles, a sample was positive and treated as negative if the $\mathrm{C}_{\mathrm{T}}$ value for $S D C 2$ methylation was undetectable. In analytic performance test for COL2A1 with serially diluted genomic DNA (HCT116), LoD was $10 \mathrm{pg}$ ( 3 genome copies) at 36 of $\mathrm{C}_{\mathrm{T}}$ value (data not shown). Thus, the test result was accepted only when the $\mathrm{C}_{\mathrm{T}}$ value of $C O L 2 A 1$ was $\leq 36$.

\section{Statistical analysis}

All statistical analysis was performed using MedCalc version 9.3.2.0 (MedCalc software, Ostend, Belgium). A $P$ value of less than 0.05 was considered statistically significant. ROC, area under ROC (AUC), and 95\% confidence intervals $(\mathrm{CI})$ were calculated. Kruskal-Wallis test was performed to compare methylation levels and clinicopathological features.

\section{Results}

\section{$S D C 2$ methylation status in various stages of colorectal} tissues

Previously, we have reported that CpG sites of $S D C 2$ regulatory region are most differentially methylated between CRC and normal tissues [20]. To know how early such aberrant $S D C 2$ methylation might occur during tumorigenesis of $C R C, S D C 2$ methylation status was analyzed using bisulfite-pyrosequencing assay in tissue lesions with various severity, including hyperplastic polyps $(n=17)$, precancerous adenomatous $(n=32)$, and colorectal tumors $(n=18)$. In addition, normal mucosal tissues $(n=5)$ were included for comparison. When determining positive call at a cutoff value of $5.0 \%$, a detection limit in pyrosequencing [23], frequency of aberrant SDC2 methylation in cancerous tissues and precancerous lesions was significantly different from that of normal mucosa $(P<0.01)$. Positive $S D C 2$ methylation was observed in $100 \%(18 / 18)$ of primary tumors, $90.6 \%$ $(29 / 32)$ of adenomas, $94.1 \%$ (16/17) of hyperplastic polyps, and $0 \%(0 / 5)$ in normal tissues. The level (MtI) of $S D C 2$ methylation was associated with increasing severity of lesions (Fig. 1). Overall mean MtI values ( \pm SD) of normal mucosa, hyperplastic polyps, adenomatous polyps, and primary tumors were estimated at $2.0 \pm 0.2$, $17.6 \pm 8.6,22.4 \pm 14.6$, and $43.5 \pm 21.0 \%$, respectively $(P<$ 0.01 ). These results indicated that $S D C 2$ methylation level was increased in accordance with severity of lesions.

\section{Development of meSDC2 LTE-qMSP assay}

Analyzing methylation status of the region of interest of target DNA, SDC2 here, in stool DNA is a formidable challenge because target DNA exists at considerably low copy number with extremely high level of background noise from unrelated genomic DNA (derived from heterogeneous origins).

To address this issue, we developed and launched this study to establish a new method demonstrating highly 


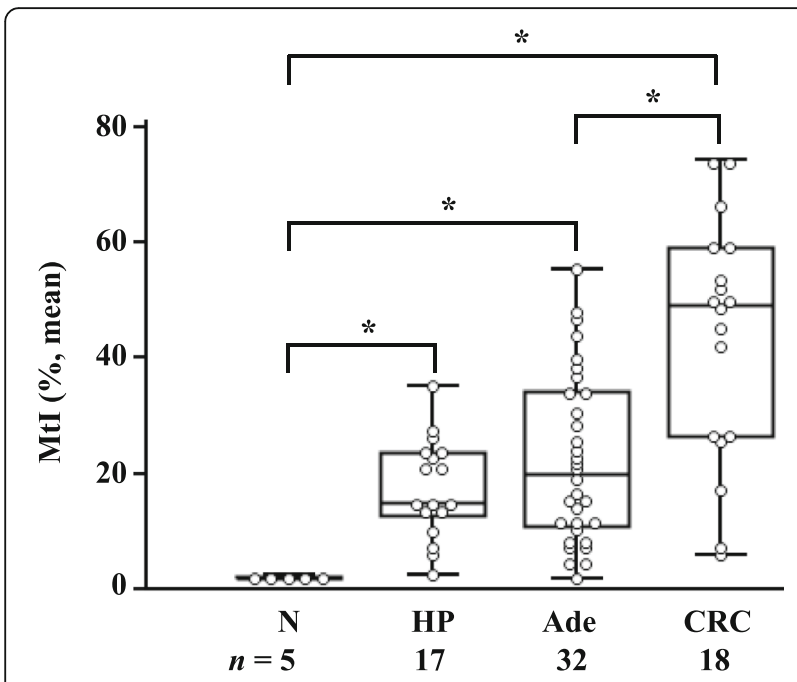

Fig. 1 Assessment of methylation levels of the SDC2 gene in colorectal tissues by bisulfite-pyrosequencing. Methylation level of the SDC2 gene was evaluated in normal mucosa (N), hyperplastic (HP) and adenomatous polyps (Ade), and CRC tissues. The Mtls of each sample are represented by box and whisker plots. The difference in Mtl of SDC2 is statistically significant at ${ }^{*} P<0.01$ calculated by Kruskal-Wallis test in adenomatous polyps vs. normal controls, hyperplastic polyps vs. normal controls, CRC vs. normal controls, and CRC vs. adenomatous polyps

sensitive and specific quantitative detection of $S D C 2$ methylation in stool DNA, named as meSDC2 LTEqMSP covering CpG targets (+377 to $+500 \mathrm{bp}$ ), outlined in Fig. 2a.

This method implements two rounds of consecutive PCR consisting of (1) unidirectional linear amplification for target DNA and control by PCR and (2) quantitative real-time PCR for methylation analysis for target region of $S D C 2$.

For the first round PCR, two primers, antisensemethylated $S D C 2$ specific and control COL2A1 specific primers with the same universal tag sequence at $5^{\prime}$ end for second round PCR were simultaneously used for linear target enrichment of $S D C 2$ methylation and control COL2A1. In the second round of PCR, conventional qMSP by real-time PCR procedure for $S D C 2$ methylation was conducted using sense $S D C 2$ specific primer and universal sequence-matched primer with methylation-specific dual labeled probe. This method was selected to optimally enhance sensitivity and diminish non-specific amplification during intensive DNA amplification and compensate for frequent artifacts seen in two round PCR. To evaluate analytic performance of new method, meSDC2 LTE-qMSP assays were conducted repeatedly (24 times) using bisulfite-treated mixture of genomic DNA (total $20 \mathrm{ng}, \sim 6200$ genome copies) as an initial template (different ratio of genomic DNA mixture), resulting in methylation percentages of
$1.0,0.5,0.25,0.1,0.05$, and $0 \%$, respectively (between fully methylated and unmethylated genomic DNA).

Regarding specificity testing, various amounts $\left(10^{5}\right.$ to $10^{9}$ copies) of plasmids (representing fully unmethylated $S D C 2$ DNA sequence) were implemented as a template for the assay. The meSDC2 LTE-qMSP detected $S D C 2$ methylation levels as low as $0.05 \%$ ( $\sim 3$ genome copies) and revealed no cross reactivity, even with excess $10^{9}$ copies of plasmids (data not shown). If LoD is defined as "a condition showing positive in more than $95 \%$ of 24 repeated assays" [26], LoD of meSDC2-qMSP was $0.1 \%$ methylation corresponding to $20 \mathrm{pg}$ ( $\sim 6$ genome copies in $\sim 6200$ copies of total template) in which detection rate was $100 \%$ (Fig. $2 b$ ).

To compare the performance of LTE-qMSP with conventional qMSP, qMSP assays (meSDC2-qMSP) for SDC2 methylation covering CpG targets (+ 377 to + $498 \mathrm{bp}$ ) [20] was evaluated in the same way with different ratio of genomic DNA mixtures, resulting in that LoD of meSDC2-qMSP was $0.5 \%$ methylation equivalent to $100 \mathrm{pg}$ ( 30 genome copies). This data indicated that LTE-qMSP assay achieved 5-fold improvement in LoD compared with qMSP for SDC2 methylation. As well, $\mathrm{C}_{\mathrm{T}}$ value for methylated $S D C 2$ was detected several cycles earlier by the meSDC2 LTE-qMSP method, when compared to that of the meSDC2-qMSP assay for all dilutions of methylated $S D C 2$ (Table 3). Linear regression analysis of meSDC2 LTE-qMSP for $S D C 2$ methylation demonstrated reproducible linearity, with a correlation coefficient of $R^{2}=0.992$ (data not shown).

\section{Feasibility test of using $S D C 2$ methylation in stool DNA- based assay for detection of CRC and precancerous lesions}

To determine whether measurement of $S D C 2$ methylation in stool DNA was capable of detecting CRC and adenoma, meSDC2 LTE-qMSP was performed using stool DNA from $50 \mathrm{CRC}$ patients at various stages and 21 patients with small size $(<1.0 \mathrm{~cm})$ of adenoma. In addition, stool DNA from 22 healthy normal subjects were included. meSDC2 LTE-qMSP showed significant higher frequency of aberrant $S D C 2$ methylation in stool DNA from both CRC $(P<0.01)$ and adenoma $(P<0.05)$ patients compared to that in healthy normal subjects (Fig. 3a). Meanwhile, 20 out of 22 healthy subjects showed an absence of methylation, indicating that $S D C 2$ methylation in stool samples had high specificity. To evaluate clinical performance of $S D C 2$ methylation in detection of CRC, ROC curve was constructed by optimizing sensitivity and specificity using assay results. ROC analysis determined optimal cutoff value of $\mathrm{C}_{\mathrm{T}}$ at 40 with AUC of 0.933 (95\% CI 0.848-0.978) (Fig. 3b). Overall sensitivity of testing for detection of CRC was 


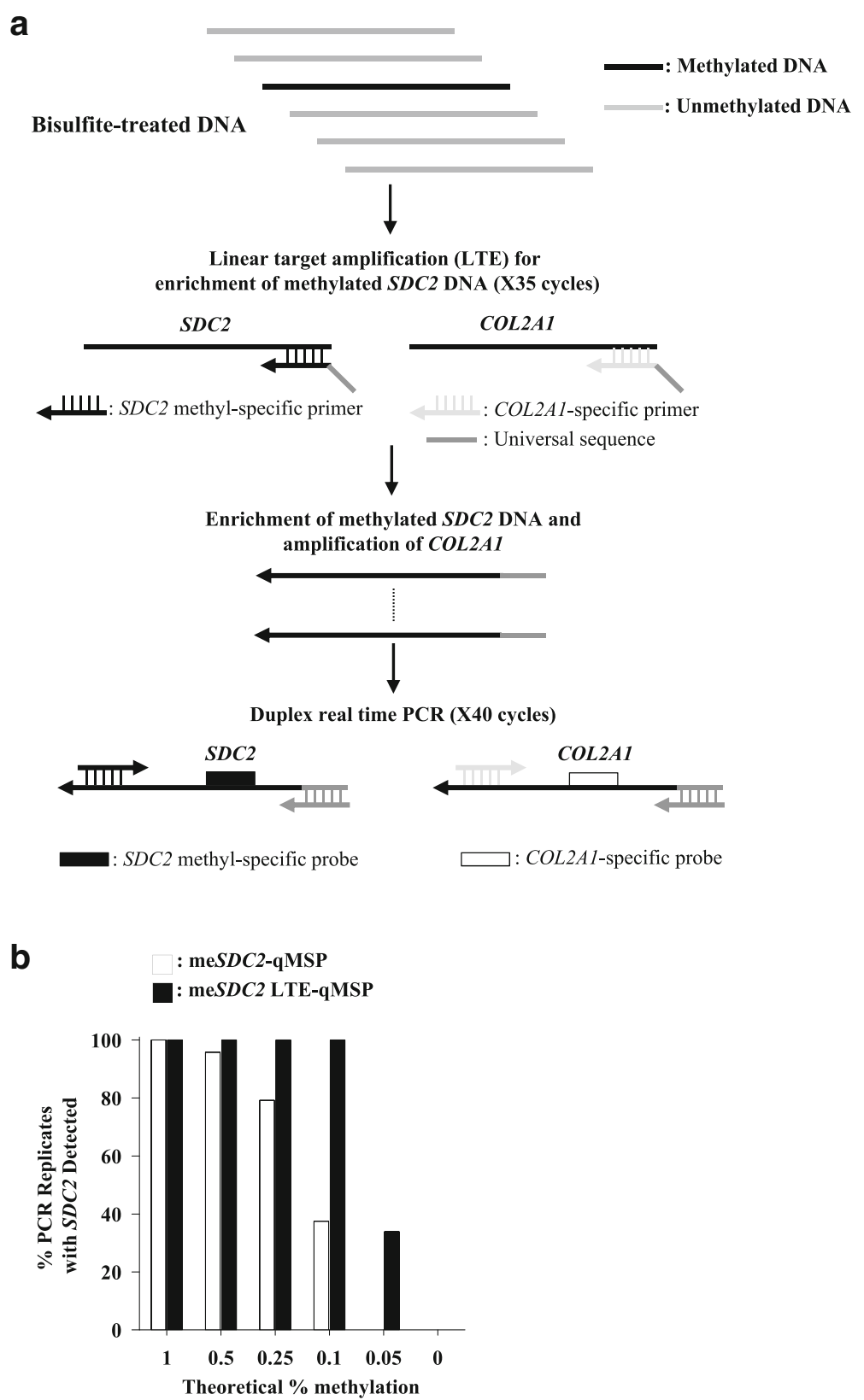

Fig. 2 Schematic diagram and analytic performance of meSDC2 LTE-qMSP. a Outline of meSDC2 LTE-qMSP. LTE was first performed using two primers: SDC2 and COL2A1 antisense primers attached to a universal primer to enrich methylated SDC2 DNA, and consecutive duplex real-time PCR was carried out using methylation-specific SDC2 sense primer, COL2A1-specific sense primer, universal primer, and probes. b The LoD of meSDC2 LTE-qMSP was compared with that of meSDC2-qMSP. Different amounts of HCT116 genomic DNA were diluted in unmethylated genomic DNA in total $20 \mathrm{ng}$ of genomic DNA

estimated at $90.0 \%(45 / 50,95 \%$ CI $78.2-96.6 \%)$ with specificity of $90.9 \%(2 / 22,95 \%$ CI $70.8-98.6 \%)$. Sensitivities for individual stages I, II, III, and IV were $83.3 \%$ (10/12), 88.2\% (15/17), 90.0\% (9/10), and 100\% $(11 / 11)$, respectively. SDC2 methylation was also detected in 7 (33.3\%) of 21 adenomas $<1.0 \mathrm{~cm}$. Thus, the sensitivity tended to be gradually increased in accordance with the severity of neoplasms.

\section{Discussion}

The results of this study indicate that quantifying the methylation level of $S D C 2$ in exfoliated epithelial cellderived DNA isolated from human stool would be a new useful noninvasive screening tool for early-stage CRC.

Screening tests have effectively reduced disease related CRC mortality, and there are currently several options available to screen the CRC. Although immunochemical 
Table 3 Comparison of analytic performance between a meSDC2 LTE-qMSP and meSDC2-qMSP

\begin{tabular}{lllll}
\hline $\begin{array}{l}\text { DNA } \\
\text { Concentration }(p g)\end{array}$ & meSDC2 LTE-qMSP detected & meSDC2 LTE-qMSP Avg C & meSDC2-qMSP detected & meSDC2-qMSP Avg C \\
\hline 200 & 24 out of 24 & 25.0 & 24 out of 24 & 32.8 \\
100 & 24 out of 24 & 26.0 & 23 out of 24 & 33.2 \\
50 & 24 out of 24 & 27.3 & 19 out of 24 & 34.9 \\
20 & 24 out of 24 & 29.6 & 9 out of 24 & 35.9 \\
10 & 8 out of 24 & 33.9 & o out of 24 & N.D \\
Negative control & 0 out of 24 & N.D & out of 24 & N.D \\
\hline
\end{tabular}

N.D not detected

FOBT is the most widely used method to detect earlystage CRC, it is limited by its low sensitivity of $65.8 \%$ [6]. A colonoscopy offers the most complete and sensitive test that is currently available. However, a colonoscopy is an invasive method to screen CRC that requires extensive bowel preparation, and it could lead to serious complications, so many patients find it undesirable. Thus, stool DNA-based molecular marker tests have been recently proposed as a new alternative to screen early-stage CRC [27].

Aberrant DNA methylation of some genes has been known to occur early during tumorigenesis. Therefore, specific methylation sites have been considered as potential biomarkers for the early diagnosis of cancer [28]. Previously, we identified that the $\mathrm{CpG}$ island of $S D C 2$ that is normally unmethylated was one of most predominantly methylated DNA sites in tumors of CRC patients, regardless of stage. The $5^{\prime}$ regulatory region of SDC2 plays a role as diagnostic biomarker for early detection of CRC because this region was frequently hypermethylated in CRC, while unmethylated in healthy normal controls. We then demonstrated that aberrant methylation status of $S D C 2$ can be readily detected in
DNA derived from the bodily fluids, such as serum and stool, of patients with CRC $[20,29]$, indicating its potential as a noninvasive molecular diagnostic biomarker for the early detection of CRC. A frequent SDC2 hypermethylation was in tissues of gastric cancer, and aberrant methylation of $S D C 2$ was correlated with diffuse-type and mixed-type gastric cancers [30]. SDC2 hypermethylation was in HPV-positive primary tumor of head and neck squamous cell cancer and glioma multiforme [31, 32]; however, details of clinical performance of SDC2 methylation test were not addressed in these studies.

In the present study, we attempted to determine whether stool DNA-based test using SDC2 methylation as a biomarker was a viable option to detect CRC. We first confirmed that the abnormal methylation of $S D C 2$ occurs in almost all CRC tissues regardless of stage and is observed also in biopsies of various precancerous lesions while not detected in normal mucosal tissues. The methylation level of SDC2 in tissue samples tend to increased according to the severity of lesions.

Developing sensitive stool DNA-based methylated DNA tests for early detection of CRC is challenging for a number of reasons. Normally, stool contains a mixture a

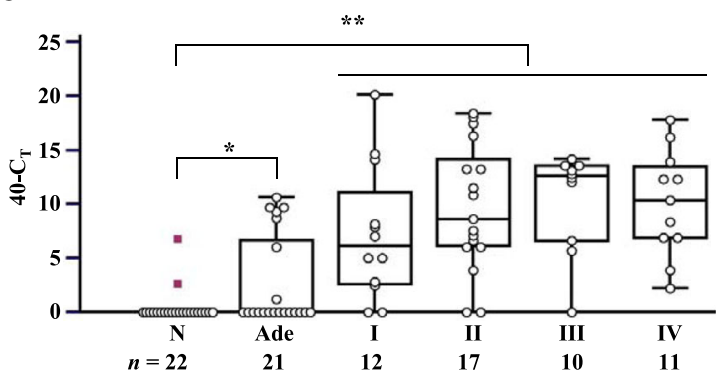

b

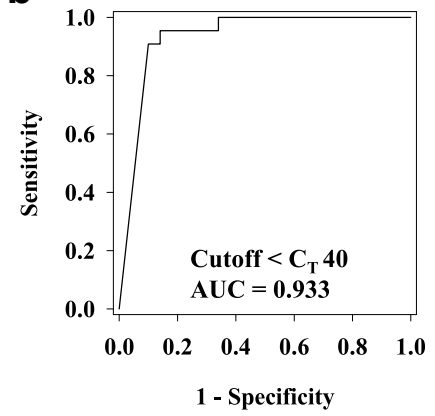

Fig. 3 Methylation status of SDC2 in stool DNA by meSDC2 LTE-qMSP test. a meSDC2 LTE-qMSP test was performed in stool DNA from CRC patients in varying stages, adenoma patients (Ade), and healthy normal subjects (N). Distribution of the relative level of SDC2 methylation was expressed in $C_{T}$ values as $40-C_{T}$ for each sample. A higher $40-C_{T}$ represents a higher methylation level of SDC2. It is represented as 0 , if the SDC2 $C_{T}$ was not detected. Methylation status of the SDC2 gene is plotted as box and whisker plots. The difference in methylation level of SDC2 was statistically significant at ${ }^{*} P<0.01$ and ${ }^{*} P<0.05$ calculated by Kruskal-Wallis test in CRC patients vs. healthy normal subjects and adenoma patients vs. healthy normal subjects, respectively. $\mathbf{b}$ ROC curve was plotted for CRC patients vs. healthy normal subjects. The cutoff value for methylation-positive and AUC are indicated in the plot 
of cells such as exfoliated epithelial cells from colon mucosa and others and in case of CRC patients a small fraction of the neoplastic cells shed from tumor lesions [33-35]. Furthermore, DNA derived from bacteria and diets tend to increase heterogeneity of stool-derived DNA [36-38]. To complicate matters, the presence of various interference/contaminating factors in the stool might inhibit PCR reactivity. Keeping in mind these various issues, we here introduced a LTE-qMSP, a highly sensitive and specific methylation detection method that employs two-step PCR procedures on bisulfite-treated purified stool DNA and combines linear target enrichment for methylated $S D C 2$ and target amplification via real-time PCR for $S D C 2$ methylation. Pyrosequencing measures methylation status of individual and multiple CpG sites. LoD of pyrosequencing is as low as 5\% fraction of methylated DNA in the background of unmethylated DNA [23]. Our new LTE-qMSP measures absolute methylation level $\left(\mathrm{C}_{\mathrm{T}}\right)$ of multiple $\mathrm{CpG}$ sites covered by methylation-specific primers and probe. LTE-qMSP has a LoD of $0.1 \%$ fraction of methylated DNA in the background of unmethylated DNA. In our preliminary study, pyrosequencing revealed low sensitivity for detection of $S D C 2$ methylation in stool DNA (data not shown). Thus, LTE-qMSP had an advantage of higher detection sensitivity for $S D C 2$ methylation compared with pyrosequencing.

In this study, we applied LTE-qMSP assay to measure $S D C 2$ methylation status in stool DNA from 50 CRCs, 21 adenomas, and 22 healthy individuals. A single reaction of meSDC2 LTE-qMSP revealed overall sensitivity of $90.0 \%$ for detection of CRC with slightly lower sensitivity for early stage than later stage CRCs with $83.3 \%$ sensitivity for stage I and a specificity of $90.9 \%$ for healthy subjects. In terms of specificity matter, $9.1 \%$ of healthy individuals revealing $S D C 2$ methylation-positive are counted as false-positive. However, considering that not all healthy subjects were verified with colonoscopy as adenomatous polyp-free and more than 30\% of asymptomatic adults older than 50 had polyps [39], possibility that those healthy subjects revealing $S D C 2$ methylation-positive have polyp(s) cannot be excluded. Specificity should be further evaluated in a number of colonoscopy-determined normal controls in future studies. In addition, we examined frequency of aberrant $S D C 2$ methylation in stool DNA from patients with a small size of adenomas $(<1.0 \mathrm{~cm})$ and estimated $33.3 \%$ of sensitivity. Notably, as compared to a single test when another reaction of meSDC2 LTE-qMSP was applied on the remaining stool DNA and the sample classified positive based on at least one positive for methylation out of the two reactions, the sensitivity increased from 33.3 to $42.9 \%$, as compared to a single test (data not shown). This suggests that multiple tests of LTE-qMSP for SDC2 methylation in stool DNA probably increase clinical sensitivity in detecting early stage of CRC as well as advanced polyps. Since the ultimate aim of screening is to prevent of CRC, screening test should be effective to detect those precancerous lesions at the risk of CRC progression [17]. When small size $(<1.0 \mathrm{~cm})$ of adenomas was detected, the patients will be generally subjected to observation. However, large adenomas $>1.0 \mathrm{~cm}$ or multiple adenomas are more likely to progress to CRC, and they are currently subjected to be removed during colonoscopy. Therefore, it will be worthy to investigate how well $S D C 2$ methylation test can detect advanced or multiple precancerous lesions in future studies.

Several groups have reported studies examining DNA methylation biomarker performance in stool DNA for early detection of CRC or precancerous lesions $[9,16$, 40, 41]. For example, SFRP2 has shown a sensitivity of $77-90 \%$ with specificity of $77 \%$ to detect CRC in stool samples, indicating an excellent sensitivity but unsatisfactory specificity [40]. HIC1 and vimentin genes have sensitivities of 42 and $46 \%$, respectively, with specificities of 100 and $90 \%$, respectively, to detect CRC in stool DNA [16, 41]. Huang et al. [4] analyzed the methylation of multiple genes (SFRP2, HPP1, and MGMT) in stool DNA from a large population. The sensitivity and specificity to detect CRC in the three combined genes was 96.2 and $95.8 \%$, respectively.

On the other hand, Ahlquist et al. [17] reported a next generation stool DNA test using multiple markers, including four methylated genes (vimentin, NDRG4, BMP3, TFPI2) and KRAS mutations. This test was able to detect $\mathrm{CRC}$ and precancerous adenoma with sensitivities of 85 and $54 \%$, respectively, at a specificity of $90 \%$ [17]. In addition, a recent study by Imperiale et al. [19] reported a stool-based multi-target test composed of seven sites of KRAS mutation, two methylation markers (NDRG4 and $B M P 3)$, and FIT. Multi-target stool testing showed a sensitivity of $92.0 \%$ to detect CRC and $42.4 \%$ for advanced precancerous lesions at a specificity of $87.0 \%$.

Mitchell et al. [42] recently performed genome-wide methylation analysis with DNA microarray in CRC tumors compared to matched-normal tissues and observed that $S D C 2$ gene was frequently methylated tumors. Subsequently they confirmed that $S D C 2$ methylation was evident in $80 \%$ or more of the tested cancer tissues by qMSP. Very recently while we were preparing this manuscript for publication, Niu et al. [18] published a paper showing that methylation tests of $S D C 2$ in fecal DNA detects CRC and advanced adenoma $(\geq 1.0 \mathrm{~cm})$ with sensitivities of 81.1 and $58.2 \%$, respectively, at a specificity of $93.3 \%$. Both data are comparable to ours and indicating that $S D C 2$ methylation event has a high potential as an early diagnostic biomarker for CRC. 
In a tissue level, $S D C 2$ methylation events have been observed in all tumor tissues of most CRC patients but have never been observed in normal colon tissues by pyrosequencing-based methylation assay having a detection limitation of 5\% [23]. In the stool DNA test, ROC analysis on assay results determined an optimal cutoff for $S D C 2$ methylation for detecting $C R C$ at $C_{T}$ value of 40. Thus, a sample was treated as positive if $C_{T}$ value for $S D C 2$ methylation was within 40 and considered as negative if the $\mathrm{C}_{\mathrm{T}}$ value for $S D C 2$ was not detectable. Healthy individuals showed a very rare frequency $(9.1 \%)$ of methylation-positive. Therefore, SDC2 methylation can be easily added to the other biomarkers reported above, thereby improves clinical performance for the early diagnosis of CRC, without losing specificity.

This study has a limitation in the small size of the patient and normal groups. Therefore, future large-scale of investigation for clinical validation of $S D C 2$ methylation and intensive evaluation of the ethnic or regional difference will be warranted.

\section{Conclusions}

We previously identified a novel potential methylation marker $S D C 2$ for the early detection of CRC. In this study, to validate $S D C 2$ methylation is able to detect patients with CRC and precancerous lesion using stool DNA, we developed a sensitive stool-based meSDC2 LTE-qMSP. Our results demonstrate that abnormal $S D C 2$ methylation is a frequent event in precancerous adenomas and CRC but is negative in normal mucosa. Our results suggest that $S D C 2$ methylation is a new potential diagnostic biomarker for noninvasive screening of CRC.

\section{Abbreviations}

CRC: Colorectal cancer; FIT: Fecal immunochemical test; FOBT: Fecal occult blood test; LoD: Limit of detection; LTE-qMSP: Linear Target Enrichmentquantitative methylation-specific PCR; Mtl: Methylation index; SDC2: The protein encoded by this gene is a transmembrane (type I) heparan sulfate proteoglycan and is a member of the syndecan proteoglycan family. The syndecan-2 protein functions as an integral membrane protein and participates in cell proliferation, cell migration, and cell-matrix interactions via its receptor for extracellular matrix proteins

\section{Acknowledgements}

We thank and gratefully acknowledge the technical assistance of staffs at Genomictree, Inc. We also thank W. Kwack at Dongguk University IIsan Hospital for his help in stool collection.

\section{Funding}

This study was supported by a grant from Ministry of SMEs and Startups (project no. S2127072), South Korea.

\section{Availability of data and materials}

The datasets analyzed during this study are available from the corresponding author on reasonable request.

\section{Authors' contributions}

SA designed the research and critically revised the article. TO, HO, and YS were responsible for data analysis and interpretation of results. TO drafted the manuscript. DC and CK prepared tissue specimens. HWK, YDH, HCC, and
NKK collected stool samples. All authors read and approved the final manuscript to be published.

\section{Ethics approval and consent to participate}

This study was approved by the Institutional Review Board of College of Medicine of Soonchunhyang University, Yonsei University College of Medicine and Dongguk University Ilsan Hospital in South Korea.

\section{Consent for publication}

Written informed consent was obtained from all study participants according to institutional guidelines.

\section{Competing interests}

TaeJeong Oh, Hyunll Oh, YangYei Seo, and Sungwhan An are employees of Genomictree, Inc. TaeJeong Oh and Sungwhan An are shareholders of Genomictree, Inc. The other authors declare that they have no competing interests.

\section{Publisher's Note}

Springer Nature remains neutral with regard to jurisdictional claims in published maps and institutional affiliations.

\section{Author details \\ ${ }^{1}$ Genomictree, Inc, 44-6 Techno 10-ro Yuseong-gu, Daejeon 34027, South Korea. ${ }^{2}$ Department of Pathology, College of Medicine, Soonchunhyang University, 23-20 Byeongmyeong-dong Dongnam-gu, Cheonan, Chungcheongnam-do 31151, South Korea. ${ }^{3}$ Department of Internal Medicine, Dongguk University Ilsan Hospital, College of Medicine, Dongguk University, 27 Dongguk-ro Ilsandong-gu, Goyang-si, Gyeonggi-do 10326, South Korea. ${ }^{4}$ Department of Surgery, Yonsei University College of Medicine, 50-1 Yonsei-ro Seodaemun-gu, Seoul 03722, South Korea. ${ }^{5}$ Yonsei Cancer Center Yonsei University College of Medicine, 50-1 Yonsei-ro Seodaemun-gu, Seoul 03722, South Korea.}

Received: 29 June 2017 Accepted: 23 November 2017

Published online: 04 December 2017

\section{References}

1. Model F, Osborn N, Ahlquist D, Gruetzmann R, Molnar B, Sipos F, et al. Identification and validation of colorectal neoplasia-specific methylation markers for accurate classification of disease. Mol Cancer Res. 2007;5(2): 153-63.

2. Jemal A, Siegel R, Ward E, Hao Y, Xu J, Thun MJ. Cancer statistics, 2009. CA Cancer J Clin. 2009;59(4):225-49.

3. Dashwood RH. Early detection and prevention of colorectal cancer. Oncol Rep. 1999:6:277-81.

4. Huang ZH, Li LH, Yang F, Wang JF. Detection of aberrant methylation in fecal DNA as a molecular screening tool for colorectal cancer and precancerous lesions. World J Gastroenterol. 2007;13(6):950-4.

5. Rex DK, Johnson DA, Anderson JC, Schoenfeld PS, Burke CA, Inadomi JM, et al. American College of Gastroenterology guidelines for colorectal cancer screening 2008. Am J Gastroenterol. 2009;104:739-50.

6. Morikawa T, Kato J, Yamaji Y, Wada R, Mitsushima T, Shiratoti Y. A comparison of the immunochemical fecal occult blood test and total colonoscopy in the asymptomatic population. Gastroenterol. 2005;129(2): 422-8.

7. Ausch C, Kim YH, Tsuchiya KD, Dzieciatkowski S, Washington MK, Paraskeva C, et al. Comparative analysis of PCR-based biomarker assay methods for colorectal polyp detection from fecal DNA. Clin Chem. 2009:55(8):1559-63.

8. Baylin SB, Herman JG, Graff JR, Vertino PM, Issa JP. Alterations in DNA methylation: a fundamental aspect of neoplasia. Adv Cancer Res. 1998;72: 141-96.

9. Zhang H, Zhu Y, Wu Y, Zhang P, Qi J. Detection of promoter hypermethylation of Wnt antagonist genes in fecal samples for diagnosis of early colorectal cancer. World J Gastroenterol. 2014;20(20):6329-35.

10. Kadiyska T, Nossikoff A. Stool DNA methylation assays in colorectal cancer screening. World J Gastroenterol. 2015;21(35):10057-61.

11. Widschwendter M, Monon U. Circulating methylated DNA: a new generation of tumor markers. Clin Cancer Res. 2006;12:7205-8. 
12. Fiegel $H$, Millinger $S$, Mueller-Holzner $E$, Marth $C$, Ensinger $C$, Berger $A$, et al. Circulating tumor-specific DNA: a marker for monitoring efficacy of adjuvant therapy in cancer patients. Cancer Res. 2005;65:1141-5.

13. Board RE, Knight L, Greystoke A, Blackhall FH, Hughes A, Dive C, et al. DNA methylation in circulating tumor DNA as a biomarker for cancer. Biomark Insights. 2008;2:307-19.

14. Wang DR, Tang D. Hypermethylated SFRP2 gene in fecal DNA is a high potential biomarker for colorectal cancer noninvasive screening. World J Gastroenterol. 2008;14(4):524-31.

15. Glöckner SC, Dhir M, Yi JM, McGarvey KE, Van Neste L, Louwagie J, et al. Methylation of TFPI2 in stool DNA: a potential novel biomarker for the detection of colorectal cancer. Cancer Res. 2009;69(11):4691-9.

16. Chen WD, Han ZJ, Skoletsky J, Olson J, Sah J, Myeroff L, et al. Detection in fecal DNA of colon cancer-specific methylation of the nonexpressed vimentin gene. J Natl Cancer Inst. 2005;97(15):1124-32.

17. Ahlquist DA, Zou H, Domanico M, Mahoney DW, Yab TC, Taylor WR et al. Next-generation stool DNA test accurately detects colorectal cancer and large adenomas. Gastroenterol 2012. Doi:https://doi.org/10.1053/j.gastro. 2011.10.031.

18. Niu F, Wen J, Fu X, Li C, Zhao R, Wu S et al. Stool DNA test of methylated syndecan-2 for the early detection of colorectal neoplasia. Cancer Epidemiol Biomark Prev 2017. doi:https://doi.org/10.1158/1055-9965. EPI-17-0153.

19. Imperiale TF, Ransohoff DF, Itzkowitz SH, Levin TR, Lavin P, Lidgard GP, et al. Multitarget stool DNA testing for colorectal-cancer screening. N Eng J Med. 2014;370(14):1287-97.

20. Oh T, Kim N, Moon Y, Kim MS, Hoehn BD, Park CH, et al. Genome-wide identification and validation of a novel methylation biomarker, SDC2, for blood-based detection of colorectal cancer. J Mol Diagn. 2013;15(4): 498-507.

21. Rapraeger AC. Sydecan-regulated receptor signaling. J Cell Biol. 2000;149: 995-8.

22. Ryu H, Lee J, Yang S, Park H, Choi S, Jung KC, et al. Syndecan-2 functions as a docking receptor for promatrix metalloproteinase-7 in human colon cancer cells. J Biol Chem. 2009;284:35692-701.

23. Dejeux E, Audard V, Carvard C, Gut IG, Terris B, Tost J. Rapid identification of promoter hypermethylation in hepatocellular carcinoma by pyrosequencing of etiologically homogeneous sample pools. J Mol Diagn. 2007;9(4):510-20.

24. Hughes $\mathrm{S}$, Jones JL. The use of multiple displacement amplified DNA as a control for methylation specific PCR, pyrosequencing, bisulfite sequencing and methylation-sensitive restriction enzyme PCR. BMC Mol Biol 2007. doi: https://doi.org/10.1186/1471-2199-8-91.

25. Kristensen LS, Mikeska T, Krypuy M, Dobrovic A. Sensitive melting analysis after real time-methylation specific PCR (SMART-MSP): high-throughput and probe-free quantitative DNA methylation detection. Nucleic Acids Res. 2008; 36(7):e42.

26. Wayne PA. CLSI. Protocols for determination of limits of detection and limits of quantitation: approved guideline. CLSI document. 2012;24(34):EP17-A2.

27. Stracci F, Zorzi M, Grazzini G. Colorectal cancer screening: tests, strategies, and perspectives. Front Public Health 2014. https://doi.org/10.3389/fpubh. 2014.00210.

28. Laird PW. The power and the promise of DNA methylation markers. Nat Rev Cancer. 2003;3(4):253-66

29. An S, Moon Y, Oh T, Chung HC. Method for detecting methylation of colorectal cancer specific methylation marker gene for colorectal cancer diagnosis. EPO Patent: 2,497,834, issued date Jan 6, 2016.

30. Chong Y, Mai-Jan K, Ryu H, Addul-Ghafar J, Munkhdelger J, Lkhagvadorj S, et al. DNA methylation status of a distinctively different subset of genes is associated with each histologic Lauren classification subtype in early gastric carcinogenesis. Oncol Rep. 2014;31(6):2535-44.

31. Worsham MJ, Chen KM, Ghanem T, Stephen JK, Divine G. Epigenetic modulation of signal transduction pathways in HPV-associated HNSCC. Otolaryngol Head Neck Surg. 2013;149(3):409-16.

32. Foltz G, Yoon JG, Lee H, Ryken TC, Sibenaller Z, Ehrich M, et al. DNA methyltransferase-mediated transcriptional silencing in malignant glioma: a combined whole-genome microarray and promoter array analysis. Oncogene. 2009;28(29):2667-77.

33. Ahlquist DA, Harrington JJ, Burgart $L$, Roche PC. Morphometric analysis of the "mucocellular layer" overlying colorectal cancer and normal mucosa: relevance to exfoliation and stool screening. Hum Pathol. 2000;31(1):51-7.

34. Johnson DH, Taylor WR, Aboelsoud MM, Foote PH, Yab TC, Cao X, et al. DNA methylation and mutation of small colonic neoplasm in ulcerative colitis and Crohn's colitis: implications for surveillance. Inflamm Bowel Dis. 2016;22(7):1559-67.

35. Zou H, Harrington JJ, Klatt KK, Ahlquist DA. A sensitive method to quantify human long DNA in stool: relevance to colorectal cancer screening. Cancer Epidemiol Biomark Prev. 2006;15(6):1115-9.

36. Whitney D, Skoletsky J, Moore K, Boynton K, Kann L, Brand R, et al. Enhanced retrieval of DNA from human fecal samples results in improved performance of colorectal screening test. J Mol Diag. 2004;6(4):386-95.

37. Roperch JP, Benzekri B, Mansour H, Incitti R. Improved amplification efficiency on stool samples by addition of spermidine and its use for noninvasive detection of colorectal cancer. BMC Biotechnol 2015. doi: 10.1186/ s12896-015-0148-6.

38. Loktionov A, O'Neill IK, Silvester KR, Cummings JH, Middleton SJ, Miller R. Quantitation of DNA from exfoliated colonocytes isolated from human stool surface as a novel noninvasive screening test for colorectal cancer. Clin Cancer Res. 1998:4(2):337-42.

39. Lieberman DA, Weiss DG, Bond JH, Ahnen DJ, Garewal H, Chejfec G, et al. Use of colonoscopy to screen asymptomatic adults for colorectal cancer. N Eng J Med. 2000;343(3):162-8.

40. Müller HM, Oberwalder M, Fiegl H, Morandell M, Goebel G, Zitt M, et al. Methylation changes in faecal DNA: a marker for colorectal cancer screening? Lancet. 2004;363(9417):1283-5.

41. Lenhard K, Bommer GT, Asutay S, Schauer R, Brabletz T, Göke B, et al. Analysis of promoter methylation in stool: a novel method for the detection of colorectal cancer. Clin Gastroenterol Hepatol. 2005;3(2):142-9.

42. Mitchell SM, Ho T, Brown GS, Baker RT, Thomas ML, McEvoy A et al. Evaluation of methylation biomarkers for detection of circulating tumor DNA and application to colorectal cancer. Genes 2016. doi:10.3390/ genes7120125.

\section{Submit your next manuscript to BioMed Central and we will help you at every step:}

- We accept pre-submission inquiries

- Our selector tool helps you to find the most relevant journal

- We provide round the clock customer support

- Convenient online submission

- Thorough peer review

- Inclusion in PubMed and all major indexing services

- Maximum visibility for your research

Submit your manuscript at www.biomedcentral.com/submit
Biomed Central 